\title{
Predictive factors for entry to long-term residential care in octogenarian Mãori and non-Māori in New Zealand, LiLACS NZ cohort
}

Marycarol Holdaway ${ }^{1}$, Janine Wiles ${ }^{2}$, Ngaire Kerse², Zhenqiang Wu ${ }^{1}$, Simon Moyes ${ }^{2}$, Martin J. Connolly ${ }^{1,3}$, Oliver Menzies ${ }^{4}$, Ruth Teh², Marama Muru-Lanning ${ }^{5}$, Merryn Gott ${ }^{6}$ and Joanna B. Broad ${ }^{1 *}$ (D)

\begin{abstract}
Background: Long-term residential care (LTC) supports the most vulnerable and is increasingly relevant with demographic ageing. This study aims to describe entry to LTC and identify predictive factors for older Māori (indigenous people of New Zealand) and non-Māori.

Methods: LiLACS-NZ cohort project recruited Māori and non-Māori octogenarians resident in a defined geographical area in 2010. This study used multivariable log-binomial regressions to assess factors associated with subsequent entry to LTC including: self-identified ethnicity, demographic characteristics, self-rated health, depressive symptoms and activities of daily living [ADL] as recorded at baseline. LTC entry was identified from: place of residence at LiLACS-NZ interviews, LTC subsidy, needs assessment conducted in LTC, hospital discharge to LTC, and place of death.

Results: Of 937 surveyed at baseline (421 Māori, 516 non-Māori), 77 already in LTC were excluded, leaving 860 participants (mean age $82.6+/-2.71$ years Māori, $84.6+/-0.52$ years non-Māori). Over a mean follow-up of 4.9 years, 278 (41\% of non-Māori, 22\% of Māori) entered LTC; of the 582 who did not, $323(55 \%)$ were still living and may yet enter LTC. In a model including both Māori and non-Māori, independent risks factors for LTC entry were: living alone $(R R=1.52,95 \% C l: 1.15-2.02)$, self-rated health poor/fair compared to very good/excellent ( $R R=1.40,95 \% C l: 1.12-1.77)$, depressive symptoms ( $R R=1.28,95 \% \mathrm{Cl}: 1.05-1.56)$ and more dependent ADLs ( $R R=1.09,95 \% C l: 1.05-1.13)$. For nonMāori compared to Māori the RR was 1.77 (95\%Cl:1.39-2.23). In a Māori-only model, predictive factors were older age and living alone. For non-Māori, factors were dependence in more ADLs and poor/fair self-rated health.

Conclusions: Non-Māori participants (predominantly European) entered LTC at almost twice the rate of Māori. Factors differed between Māori and non-Māori. Potentially, the needs, preferences, expectations and/or values may differ correspondingly. Research with different cultural/ethnic groups is required to determine how these differences should inform service development.
\end{abstract}

Keywords: Long-term care, Advanced age, Risk factors, Care transition, Ethnic differences, Health services, Indigenous peoples

\footnotetext{
* Correspondence: j.broad@auckland.ac.nz

${ }^{1}$ Department of Geriatric Medicine, University of Auckland, C/- Waitematā District Health Board, Takapuna, PO Box 93 503, Auckland, New Zealand

Full list of author information is available at the end of the article
}

(c) The Author(s). 2021 Open Access This article is licensed under a Creative Commons Attribution 4.0 International License, which permits use, sharing, adaptation, distribution and reproduction in any medium or format, as long as you give appropriate credit to the original author(s) and the source, provide a link to the Creative Commons licence, and indicate if changes were made. The images or other third party material in this article are included in the article's Creative Commons licence, unless indicated otherwise in a credit line to the material. If material is not included in the article's Creative Commons licence and your intended use is not permitted by statutory regulation or exceeds the permitted use, you will need to obtain permission directly from the copyright holder. To view a copy of this licence, visit http://creativecommons.org/licenses/by/4.0/ The Creative Commons Public Domain Dedication waiver (http://creativecommons.org/publicdomain/zero/1.0/) applies to the data made available in this article, unless otherwise stated in a credit line to the data. 


\section{Background}

Despite attempts in many countries to reduce use of long-term residential care (LTC), utilisation is common with increasing age $[1,2]$. LTC facilities provide accommodation and support for people whose needs for care surpass what is manageable at home with care/support from unpaid/paid carers. Terminology for residential aged care varies by country and level of care. Terms include nursing homes and geriatric hospital care, (for those with high dependency care needs); hostels, residential homes, rest homes, assisted living, (for those who need low dependency care needs,) and dementia care and psychogeriatric care. In this paper LTC refers to low, high, dementia and psychogeriatric care residential facilities, for both short and long-term care. Factors identified as predicting entry to LTC vary according to the availability of services and where and how studies are conducted [2].

Throughout the member countries of the OECD (Organisation for Economic Co-operation and Development), demand for LTC services is expected to increase because the number of people aged $85+$ years is rising rapidly. For example, in Aotearoa New Zealand (NZ), official estimates expect numbers aged 85+ will triple, from 75,000 in 2013 to 230,040 by 2040 [3]. In NZ, over two-thirds of people reaching 85 years eventually move into a LTC facility [4]. Understanding service demand is important in countries that have a universal healthcare system such as NZ where all residents have access to healthcare without requiring private health insurance. International comparisons demonstrate more than ten-fold variation in use of LTC $[5,6]$ Utilisation is related to regional availability of facilities [7], specific disease states such as diabetes [8], differences by country/region and between cultural, religious, ethnic and/or racial groups [2]. In the USA, ethnic minorities and indigenous people enter LTC with poorer health than their European-majority counterparts [9]. Disparities in health outcomes of older indigenous people are often described [10-12] but seldom become a population-based research focus.

This study is drawn from Life and Living in Advanced Age: A Cohort Study in New Zealand - Te Puawaitanga o Nga Tapuwae Kia Ora Tonu study (LiLACS-NZ) which draws from a population-based sampling frame with indigenous (aged 80-90 years) and non-indigenous (aged 85 years) cohorts of similar size designed to provide similar statistical power. LiLACS-NZ aims to identify predictors of successful advanced ageing for Māori and non-Māori $[13,14]$ through acknowledging Māori methods and ideologies. Māori culture and Māori kaumātua (elders, both genders) are important components of the cultural fabric of NZ society. Kaumātua hold leadership roles in their whānau (extended family), hapū (sub-tribe), and iwi (tribe). They act as guardians of tikanga (Māori customs and practices) and are generally well respected in their communities [15]. In turn, whānau have cultural obligations to care for and support their kaumātua, sometimes at considerable personal cost [16].

Most commonly reported risk factors for LTC entry are those that constrain independent living: impaired mobility and inability to complete simple tasks such as washing, toileting, shopping, cooking and other ADLs are consistently identified [2]. Other relevant factors include living alone and recurrent falls, both associated with safety [17-19]. Older age is also a strong predictor of LTC [20], however few studies predicting LTC entry focus on the oldest old $(80+)$ [21]. Importantly, risk factors for entry to LTC may differ for people aged $80+$ compared to younger age groups. In a German study, cognitive and functional impairment predicted entry for younger old people $(<80$ years) but not for those aged over 82 years [22]. In NZ, research on the topic was limited to small and/or focused studies, [23, 24] but recently a study by Jamieson et al. evaluating social factors influencing LTC entry in those receiving a support needs assessment, found that living alone, negative social interactions, perceived loneliness and carer stress were independently associated with higher likelihood of LTC admission [25]. Further, whether predictive factors for LTC entry apply similarly to all ethnic groups, or why some ethnic groups use LTC less often than others, is largely unaddressed.

Inequities in social determinants of health and healthcare access drive large health and mortality disparities between Māori and non-Māori [26, 27]. Currently, the majority of LTC residents in NZ are European, with few older Māori residents. In 2013, 5.6\% of the population aged $65+$ were Māori, and $87.8 \%$ were European [28]. Of those in LTC, however, just 3.3\% were Māori, with 93.4\% European [29]. In the LiLACS-NZ study, baseline data showed that, of those with frequent and high levels of need for care, Māori were less likely to be living in LTC [30, 31]. Further, in the study of carers of LiLACSNZ, Māori received significantly more hours of informal (unpaid) care e.g. from family, than non-Māori, and Māori carers were more likely to live in the same house or on the same property [30]. Living in multigenerational family settings means they are less likely to qualify for formal home support (e.g. help with shopping, travel for medical attention, or household cleaning), thus perversely leading to further disparities in access to formal supports for Māori. Indeed, access to formal home support at baseline in LiLACS-NZ also differed, with Māori receiving formal care being discernably more disabled than those not receiving formal care, a distinction not holding for non-Māori [31]. Whānau has traditionally been an integral part of health for Māori, and indeed the popular Te Whare Tapa Whā [32] model 
of Māori health notes whānau as one of the four mainstays of health for Māori. One of the recognised roles of whannau is that it "looked after its own aged or disabled members" [33]. How these differences in care patterns and cultural priorities may play out when accessing LTC is the subject of this report.

In line with other countries, NZ urgently needs better understanding of health, demographic and socio-cultural factors that explain ethnic differences in healthcare use, including entry to LTC. The main aims of this prospective study using the LiLACS-NZ cohorts were to assess the proportion who entered LTC over the study period and to identify independent risk factors for LTC entry among NZ Māori and non-Māori octogenarians.

\section{Methods}

\section{Study design}

LiLACS-NZ is a bicultural cohort study of people in advanced age, by design enrolling non-Māori in their 85th year, and Māori aged 80-90 years [13, 34]. Geographical boundaries of the District Health Boards (DHB) of the Bay of Plenty and northern part of the Lakes areas were chosen as having a stable population, with mixed urban and rural populations including Māori communities. General practitioners and Hauora Māori (Māori health services) provide primary healthcare, while secondary care services are provided by public hospitals in two cities and one town. Local municipal councils have no direct role in health service or LTC provision.

At baseline, there were 421 (45\%) Māori and 516 (55\%) non-Māori [13, 34]. Study participants completed full (long) or core (short) interviews annually from 2010 until 2016, death, or dropout. Participants who were unable to complete a full interview due to illness or other restrictions completed the core interview. Most participants also completed medical reviews, blood tests and physical assessments yearly. Participants who chose the core interview did not have a physical assessment or blood tests.

LiLACS-NZ was guided by the Te Rōpū Kaitiaki o Ngā Tikanga Māori (Protectors of Principles of Conduct in Māori Research, Māori guidance group) who advised on interview content, conduct, etiquette and translation [13]. Interviews and physical assessments were undertaken by trained lay interviewers and nurses respectively, using standardised procedures. Primary care medical records and secondary care hospital records were accessed with consent $[13,35]$.

\section{Entry to LTC}

The endpoint of LTC entry was defined as any reported transition into lower-level (rest home or specialist dementia care) or higher-level care (private hospital or psychogeriatric care), at any time after baseline interview.
With no single authoritative information source available, to maximise completeness, LTC entry was established from any one or more of six sources: 1) place of residence from six waves of LiLACS-NZ interviews; 2) late life residence or place of death in LILACS-NZ endof-life interviews; 3) discharge destination in Ministry of Health $(\mathrm{MoH})$ hospitalisation discharge data; 4) receipt of long-term care subsidy from Contracted Care Payment System (CCPS) subsidy data; 5) healthcare needs assessment conducted while resident in LTC from interRAI (international Resident Assessment Instrument) Long Term Care Facility (LTCF) assessments [36]; and 6) place of death from the $\mathrm{MoH}$ National Mortality Collection Registry data. Follow up was from study baseline in 2010 to December 2016. Because of data limitations, both short- and long-term stays were included as LTC, though short-term residential care is rarely used in NZ. For a comprehensive explanation of the primary data sources (see Additional file 1).

\section{Risk factors for LTC entry}

Potential predictive factors investigated were identified from the baseline questionnaires, primary care medical record review, blood test results and physical assessment [13]. Following discussion among authors and literature review, important factors for investigation were identified and where possible included in the investigation. Due to data limitations, factors reported from both core and full questionnaires only were included. Gender, marital status, and living arrangement were established at cohort inception by self-report. Ethnicity was established by self-identification using the NZ census question 2006 [37]. Self-rated health was from a single question in the SF-12 [38], falls were by self-report, and ADL function was from 11 questions from the NEADL scale [39] relating to the following areas: mobility, activities in the kitchen, domestic tasks, leisure activities and basic tasks (personal care, toileting, moving in and out of bed). Depressive symptoms were derived from the GDS [40] with a threshold $\geq 5$ and/or from depressive symptoms (see Additional file 1). Those factors significantly associated with the endpoint in unadjusted exploratory logistic regressions were investigated in adjusted models.

\section{Statistical analysis}

Scaled rectangle diagrams were used to visualise primary data sources of LTC transition events captured, and the overlap between them [41]. T-tests and chi-square tests were conducted to assess the association of LTC entry and individual predictive factors. Variables that were significant $(p$ value $\leq 0.05)$ in univariate analyses and/or important in international studies were modelled for the whole cohort, and in separate models for Māori and 
non-Māori. Multivariable log-binomial regressions were used to identify significant independent predictive factors for entry to LTC and estimate the associated relative risk (RR) [42]. The modelled $R^{2}$ assessed goodnessof-fit [43].

Analyses were performed using SAS version 9.4 (SAS Institute Inc., Cary, NC, USA) or R ( $\mathrm{R}$ package version 3.3.1.). Significance testing used two-sided tests, with $p \leq 0.05$ considered significant.

\section{Results}

\section{Baseline characteristics}

Of 937 people recruited and interviewed, 77 were already in LTC at baseline (30 Māori, 47 non-Māori) and were excluded from analyses (Fig. 1). Of the 860 Māori and non-Māori remaining, 55\% were female, with $62 \%$ not married (i.e. single/widowed) (Table 1). Mean age was 82.6 (Standard Deviation (SD) 2.71) years for Māori and 84.6 (SD 0.52) years for non-Māori. At baseline, at least $40 \%$ were living with others, $43 \%$ reported very good/excellent health, $18 \%$ reported falling $\geq 2$ times per year; with help needed to perform 1.4 ADLs on average (Table 1).

\section{Deaths and entry to long-term care}

When all information sources were combined over a mean follow-up time of 4.9 years, 454 (53\%) died (222 Māori, 232 non-Māori). One or more records of a transition to LTC was found for 278 (32\%): 87 (22\%) Māori and 191 (41\%) non-Māori (Table 2, $p<0.0001)$. LiLACS-NZ interviews in waves $2-6$ captured $76(27 \%)$ of the 278 known transitions to LTC after baseline (Table 2). One or more $\mathrm{MoH}$ sources yielded almost all $(n=275)$ transitions, though no single source found more than 7 in 10 transitions; few were sourced from hospital discharge destination data (Fig. 2). No LTC indication was found for 582 participants and of these, $45 \%$ died during the followup period (154 of 304 Māori, 51\%, and 105 of 278 nonMāori, $38 \%, p=0.002$ ).

Unadjusted associations of potential predictive factors for entry to LTC showed all variables in Table 1, except gender, were significantly associated with LTC entry either for Māori, non-Māori, or when combined (Table 3). For Māori, statistically significant variables were age, self-rated health, depressive symptoms and dependency in ADLs, and for non-Māori, marital status, living situation, self-rated health, depressive symptoms, falls and dependency in ADLs (Table 3).

Multivariable models included all significant variables identified from the univariate analyses, then falls was removed as non-contributing to the model fit. In the multivariable model of all 860 participants living in the community at baseline, non-Māori had almost twice the likelihood of LTC entry than Māori $(\mathrm{RR}=1.77,95 \% \mathrm{CI}$ : 1.39-2.23, $p$-value <0.001, Table 4). Reporting poor/fair health compared to very good/excellent health, and depressive symptoms compared to not, were also associated with greater likelihood of LTC entry $(\mathrm{RR}=1.40$ and 1.28 , respectively).

Predictive factors for entry to LTC for Māori \& non-Māori In the multivariable model of Māori participants only, older age and living alone were significant independent predictors of admission to LTC (Table 4). In the

77 participants in LTC at baseline excluded

937 baseline participants

(421 Māori, 516 non-Māori)

(30 Māori, 47 non-Māori)

860 were not in LTC at baseline,

\& were included in this study

582 had no record of entry to LTC

(304 Māori, 278 non-Māori)

- 259 died during follow up period

- 323 were alive and might yet enter LTC

278 moved into LTC after baseline

(87 Māori, 191 non-Māori)

- 195 died during follow up period

Fig. 1 Entry to LTC study flowchart 
Table 1 Baseline participant characteristics for All, Māori and non-Māori participants living at home

\begin{tabular}{|c|c|c|c|}
\hline & $\begin{array}{l}\text { All participants } \\
N=860\end{array}$ & $\begin{array}{l}\text { Māori } \\
N=391\end{array}$ & $\begin{array}{l}\text { Non-Māori } \\
N=469 \\
\end{array}$ \\
\hline Age, mean (SD) & $83.7(2.12)$ & $82.6(2.71)$ & $84.6(0.52)$ \\
\hline Women, n (\%) & $472(55)$ & $223(57)$ & $249(53)$ \\
\hline Not-married, n (\%) & $534(62)$ & $265(68)$ & $269(57)$ \\
\hline \multicolumn{4}{|l|}{ Living situation, n (\%) } \\
\hline Alone & $296(34)$ & $109(28)$ & $189(40)$ \\
\hline With others & $348(40)$ & $156(40)$ & $192(41)$ \\
\hline Unknown (Core questionnaire) & $214(25)$ & $126(32)$ & $88(19)$ \\
\hline \multicolumn{4}{|l|}{ Self-rated health, n (\%) } \\
\hline Poor/fair & $178(21)$ & $83(21)$ & $95(20)$ \\
\hline Good & $313(36)$ & $141(36)$ & $172(37)$ \\
\hline Very good/excellent & $369(43)$ & $167(43)$ & $202(43)$ \\
\hline Depressive symptoms, n (\%) & $246(29)$ & $139(36)$ & $110(23)$ \\
\hline Two or more falls in last 12 months, $n$ (\%) & $158(18)$ & $68(17)$ & $90(19)$ \\
\hline ADLs, mean (SD) & $1.41(1.95)$ & $1.58(2.35)$ & $1.27(1.52)$ \\
\hline
\end{tabular}

Note: Participants in LTC at baseline interview $(n=77)$ are excluded. Depressive symptoms is indicated if participant's Geriatric Depression Scale score $\geq 5$ or where participant reports feeling depressed recently. ADLs is a count of 11 tasks participants did not perform independently from the Nottingham Extended Activities of Daily Living scale. SD = standard deviation

multivariable model for non-Māori only, poor/fair self-rated health and greater dependency in ADLs were significant independent predictors of admission to LTC.

Differences in significant predictive factors were noted: living alone status was associated with greater likelihood of entry to LTC among Māori (RR = 1.72, 95\%CI:1.062.80) but did not reach significance for non-Māori (RR = 1.41, 95\%CI:0.99-2.03); greater functional dependence at baseline was important for non-Māori ( $R R=1.14$, 95\%CI:1.09-1.19) but not Māori. Measures of model fit showed that the three models had only modest fit $\left(\mathrm{R}^{2}=\right.$ 0.06 to 0.11 , Table 4 ).

\section{Discussion}

This is the first study to examine prospectively the likelihood of LTC placement for a large group of very old indigenous people. Within the context of advanced ageing in Aotearoa NZ, we show that LTC is used less frequently by indigenous peoples (Māori) and also that the risk factors differ between the indigenous and nonindigenous peoples. These findings add to both the

Table 2 Death and Entry to long-term care in LiLACS NZ cohort, by source of information

\begin{tabular}{|c|c|c|c|}
\hline & $\begin{array}{l}\text { All Participants } \\
N=860\end{array}$ & $\begin{array}{l}\text { Māori } \\
N=391\end{array}$ & $\begin{array}{l}\text { Non-Māori } \\
N=469\end{array}$ \\
\hline Follow-up time, mean years (SD) & $4.86(1.94)$ & $4.65(1.87)$ & $5.03(2.00)$ \\
\hline Died during follow-up, $\mathrm{n}$ (\%) & $454(53)$ & $222(57)$ & $232(49)$ \\
\hline Entry to LTC, n (\%) & $278(32)$ & $87(22)$ & $191(41)$ \\
\hline No entry to LTC, $\mathrm{n}(\%)$ & $582(68)$ & $304(78)$ & $278(59)$ \\
\hline LiLACS NZ interviews, n (\%) & $76(9)$ & $23(6)$ & $53(11)$ \\
\hline Waves 2-6 participant interviews & $63(7)$ & $18(5)$ & $45(10)$ \\
\hline End of Life Interviews & $23(3)$ & $9(2)$ & $14(3)$ \\
\hline Ministry of Health sources, n (\%) & $275(32)$ & $84(21)$ & $191(41)$ \\
\hline CCPS subsidy & $199(23)$ & $60(15)$ & $139(30)$ \\
\hline interRAl assessments & $148(17)$ & $44(11)$ & $104(22)$ \\
\hline Mortality registry & $90(10)$ & $31(8)$ & $59(13)$ \\
\hline Hospital discharge & 26 (3) & 7 (2) & $19(4)$ \\
\hline
\end{tabular}

Note: 77 participants (30 Mãori, 47 non-Māori) who were resident in LTC at baseline were excluded 


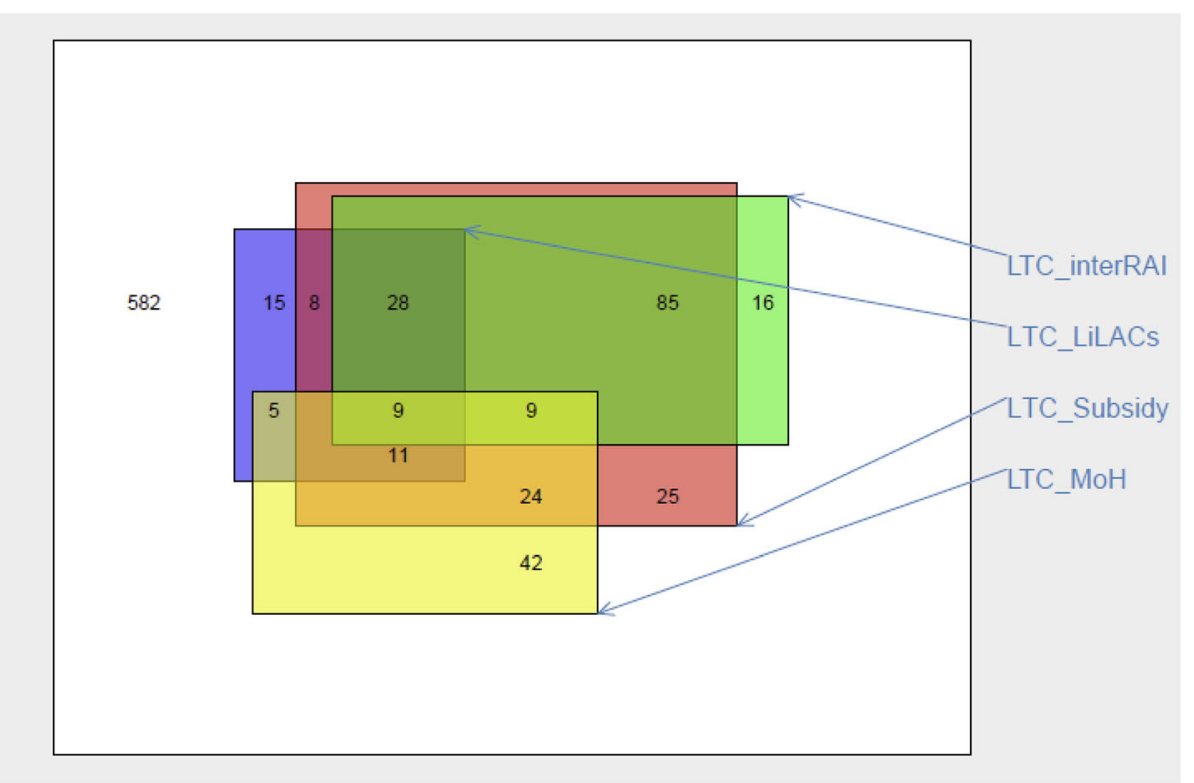

Fig. 2 Entry to long-term care by source of information. Scaled rectangle diagram demonstrating LTC entry during follow-up, as captured by each of four data sources, showing their intersections. LTC_interRAl indicates an interRAl assessment conducted in/for a LTC facility. LTC_LiLACS represents LTC entry recorded in any LiLACs_NZ interview. LTC_Subsidy indicates government subsidy payments made for this person. LTC_MoH represents a LTC entry recorded in Ministry of Health hospitalizations data and/or National Mortality Collection Registry data

international evidence regarding factors leading to LTC placement [2] and to the dialogue on health services for indigenous peoples [11]. It is evident that non-Māori and Māori in NZ use LTC in different ways, possibly partly because family and whānau support for older family members differs between indigenous and nonindigenous New Zealanders.

Likelihood of entry to LTC for non-Māori is approaching double that for Māori when adjusted for other factors: age, gender, marital status, living situation, selfrated health, depressive symptoms and functional status. Furthermore, in ethnic specific models, Māori and nonMāori had different profiles of factors associated with subsequent LTC entry. For example, living alone at baseline predicted LTC entry for Māori but not for nonMāori, and dependency in ADLs was associated with subsequent LTC entry among non-Māori but not among Mãori. This is contrary to most other studies where functional limitation is found to be the primary driver of transition [2]. Other factors, measured and/or unmeasured, may also play a role.

Cultural perspectives are relevant to the search for reasons for the observed differences. That fewer Māori entered LTC over almost 5 years of follow-up may illustrate the impact of Māori cultural practices of whanaungatanga (family connection), manaakitanga (caring for and respecting others) and āwhina (supporting others) whereby whānau have obligations and responsibilities to care for their kaumātua. Those cultural expectations to provide informal support may contribute to fewer Māori receiving formal home-based services (despite worse health), more common use of informal care and less use of LTC, by Māori [31]. Living alone was a stronger factor in LTC placement for Māori than nonMāori, suggesting that the impact of whānau and family care meant for some Māori entry to LTC was delayed or avoided. Anecdotal reports of Māori whānau members moving house (and country) specifically to provide informal care to support kaumātua could not be examined in this analysis, however, these cultural obligations and observed differences in patterns of care, as in baseline data [30,31, 44], are likely to be relevant to the observed difference in rate of admission to LTC. However, the extent to which Māori whānau will continue to find capacity to provide care into the future is unclear given changing family structures and increased care demands due to rising numbers of kaumātua and their increasing longevity [28]. Older Māori are also less able to access primary care services due to the cost of primary care in NZ [45], thus community support for Māori may need to be strengthened.

We are also unable, in this analysis, to establish whether differential access to home-based supports or culturally driven preferences are the main drivers of LTC entry. While culture-related care patterns may contribute to the lack of association between ADL level and entry to LTC among Māori, other questions are also likely to be relevant. Do Māori who enter LTC find the environment (staff, other residents, systems, food, buildings and gardens) inclusive and accepting of non- 
Table 3 Entry to long-term care by baseline characteristics, unadjusted comparisons

\begin{tabular}{|c|c|c|c|c|c|c|c|c|c|}
\hline & \multicolumn{3}{|c|}{ All Participants } & \multicolumn{3}{|l|}{ Māori } & \multicolumn{3}{|l|}{ non-Māori } \\
\hline & $\begin{array}{l}\text { no LTC } \\
n=582\end{array}$ & $\begin{array}{l}\text { LTC } \\
n=278\end{array}$ & $P$ value & $\begin{array}{l}\text { no LTC } \\
n=304\end{array}$ & $\begin{array}{l}\text { LTC } \\
n=87\end{array}$ & $P$ value & $\begin{array}{l}\text { no LTC } \\
n=278\end{array}$ & $\begin{array}{l}\text { LTC } \\
n=191\end{array}$ & $P$ value \\
\hline \multicolumn{10}{|l|}{ Ethnicity, n (\%) } \\
\hline Māori & $304(52)$ & $87(31)$ & $<0.001$ & $304(100)$ & $87(100)$ & & - & - & - \\
\hline Non-Māori & $278(48)$ & $191(69)$ & & - & - & & $278(100)$ & $191(100)$ & \\
\hline Age, mean (SD) & $83.4(2.2)$ & $84.2(1.8)$ & $<0.001$ & $82.4(2.6)$ & $83.2(2.9)$ & 0.01 & $84.6(0.5)$ & $84.6(0.5)$ & 0.44 \\
\hline \multicolumn{10}{|l|}{ Gender, n (\%) } \\
\hline Women & $318(55)$ & $154(55)$ & 0.83 & $175(58)$ & $48(55)$ & 0.69 & $143(51)$ & $106(55)$ & 0.39 \\
\hline Men & $264(45)$ & $124(45)$ & & $129(42)$ & $39(45)$ & & $135(49)$ & $85(45)$ & \\
\hline \multicolumn{10}{|l|}{ Marital status, n (\%) } \\
\hline Not-married & $350(60)$ & $184(66)$ & 0.09 & $204(67)$ & $61(70)$ & 0.60 & $146(53)$ & $123(64)$ & 0.01 \\
\hline Married & $232(40)$ & $94(34)$ & & $100(33)$ & $26(30)$ & & $132(47)$ & $68(36)$ & \\
\hline \multicolumn{10}{|l|}{ Living situation, n (\%) } \\
\hline Alone & $183(31)$ & $115(41)$ & 0.001 & $78(26)$ & $31(36)$ & 0.16 & $105(38)$ & $84(44)$ & 0.001 \\
\hline With others & $259(45)$ & $89(32)$ & & $127(42)$ & $29(33)$ & & $132(47)$ & $60(31)$ & \\
\hline Unknown (Core) ${ }^{a}$ & $140(24)$ & $74(27)$ & & $99(33)$ & $27(31)$ & & $41(15)$ & $47(25)$ & \\
\hline \multicolumn{10}{|l|}{ Self-rated health, n (\%) } \\
\hline Poor/fair & $96(16)$ & $82(29)$ & $<0.001$ & $56(18)$ & $27(31)$ & 0.04 & $40(144)$ & $55(29)$ & $<0.001$ \\
\hline Good & $218(37)$ & $95(34)$ & & $113(37)$ & $28(32)$ & & $105(38)$ & $67(35)$ & \\
\hline Very good/excellent & $268(46)$ & $101(36)$ & & $135(44)$ & $32(37)$ & & $133(48)$ & $69(36)$ & \\
\hline \multicolumn{10}{|c|}{ Depressive symptoms, n (\%) } \\
\hline Yes & $147(25)$ & $99(36)$ & 0.002 & $97(32)$ & $39(45)$ & 0.03 & $50(18)$ & $60(31)$ & $<0.001$ \\
\hline No & $435(75)$ & $179(64)$ & & $207(68)$ & $48(55)$ & & $228(82)$ & $131(69)$ & \\
\hline \multicolumn{10}{|c|}{ No. of falls in last 12 months, $n(\%)$} \\
\hline $2+$ falls & $91(16)$ & $67(24)$ & 0.003 & $49(16)$ & $19(22)$ & 0.21 & $42(15)$ & $48(25)$ & 0.007 \\
\hline 0,1 fall & 491 (84) & $211(76)$ & & $255(84)$ & $68(78)$ & & $236(85)$ & $143(75)$ & \\
\hline ADLs, mean (SD) & $1.21(1.85)$ & $1.82(2.08)$ & $<0.001$ & $1.45(2.33)$ & $2.03(2.38)$ & 0.04 & $0.96(1.04)$ & $1.72(1.93)$ & $<0.001$ \\
\hline
\end{tabular}

Note: Participants in LTC at baseline interview $(n=77)$ are excluded. Continuous variables are reported as mean (SD); categorical variables are reported as $n$ (\%). Depressive symptoms is indicated if Geriatric Depression Scale score $\geq 5$ or where participant reports feeling depressed recently. ADLs is a count of 11 tasks participants did not perform independently from the Nottingham Extended Activities of Daily Living scale. $P<0.05$ is indicated in bold. SD $=$ standard deviation a The relationship between completing the LiLACS NZ core questionnaire and LTC entry is examined as a variable in living situation because participants who completed a core questionnaire had missing data about living situation

European traditions, values and practices? Are LTC institutions able to support and embrace Māori tikanga appropriately? For people in advanced age of any ethnicity, how can family/whānau who provide home-based informal care, often at the loss of careers and income $[30,46]$ be better supported with health service navigation, skill development (for formal and informal carers) and/or financial assistance [47]. Public discussion is urgently needed regarding access and appropriateness of support services for people of advanced age whether in LTC settings or at home.

There are three additional learnings from this study. Firstly, and consistent with international data, depressive symptoms (as measured by western tools), predicts LTC entry for all participants [48, 49]. Depression has been recognised as sufficient to overwhelm an older person and their support network [50], resulting in escalation in need and entry to LTC [48]. Jamieson et al. confirmed this for NZ in a large study of a higher risk group than the current study, and in which Māori were only half as likely to enter LTC [25]. Risk of entry was 13\% higher when the person was depressed, and $28 \%$ higher when the carer scored high on a measure of carer stress [25]. Primary care practitioners, practice nurses and community members could be encouraged to recognise and address depressive symptoms in order to avert escalation to LTC, but research is needed to better understand depressive symptoms and coping mechanisms in different cultural settings.

Secondly, supporting a recent systematic review [2] and other NZ research [25], and despite the preponderance of women in care facilities [29], neither gender was at greater 
Table 4 Multivariable models of baseline characteristics to predict LTC entry

\begin{tabular}{|c|c|c|c|}
\hline & $\begin{array}{l}\text { All participants } \\
N=860\end{array}$ & $\begin{array}{l}\text { Māori } \\
N=391\end{array}$ & $\begin{array}{l}\text { Non-Māori } \\
N=469\end{array}$ \\
\hline & $\begin{array}{l}\text { RR }(95 \% \mathrm{Cl}) \\
p \text {-value }\end{array}$ & $\begin{array}{l}\text { RR }(95 \% \mathrm{Cl}) \\
p \text {-value }\end{array}$ & $\begin{array}{l}\text { RR }(95 \% \mathrm{Cl}) \\
p \text {-value }\end{array}$ \\
\hline Non-Māori (vs Māori) & $\begin{array}{l}1.77(1.39,2.23) \\
<\mathbf{0 . 0 0 1}\end{array}$ & - & - \\
\hline Age (each year of age) & $\begin{array}{l}1.06(1.00,1.12) \\
0.07\end{array}$ & $\begin{array}{l}1.08(1.01,1.15) \\
\mathbf{0 . 0 2}\end{array}$ & $\begin{array}{l}0.99(0.80,1.21) \\
0.90\end{array}$ \\
\hline Men (vs women) & $\begin{array}{l}1.01(0.83,1.23) \\
0.89\end{array}$ & $\begin{array}{l}1.10(0.75,1.63) \\
0.62\end{array}$ & $\begin{array}{l}1.01(0.81,1.26) \\
0.94\end{array}$ \\
\hline Not-married (vs married) & $\begin{array}{l}1.00(0.77,1.29) \\
0.97\end{array}$ & $\begin{array}{l}0.86(0.55,1.34) \\
0.50\end{array}$ & $\begin{array}{l}1.10(0.79,1.54) \\
0.56\end{array}$ \\
\hline \multicolumn{4}{|l|}{ Living situation } \\
\hline Alone (vs with others) & $\begin{array}{l}1.52(1.15,2.02) \\
\mathbf{0 . 0 0 4}\end{array}$ & $\begin{array}{l}1.72(1.06,2.80) \\
\mathbf{0 . 0 3}\end{array}$ & $\begin{array}{l}1.41(0.99,2.03) \\
0.06\end{array}$ \\
\hline Unknown ${ }^{a}$ (vs with others) & $\begin{array}{l}1.31(1.00,1.71) \\
0.05\end{array}$ & $\begin{array}{l}1.07(0.67,1.71) \\
0.76\end{array}$ & $\begin{array}{l}1.41(0.98,2.04) \\
0.07\end{array}$ \\
\hline \multicolumn{4}{|l|}{ Self-rated health } \\
\hline Poor/fair (vs v.good/excellent) & $\begin{array}{l}1.40(1.12,1.77) \\
\mathbf{0 . 0 0 4}\end{array}$ & $\begin{array}{l}1.53(0.98,2.41) \\
0.06\end{array}$ & $\begin{array}{l}1.38(1.06,1.80) \\
\mathbf{0 . 0 2}\end{array}$ \\
\hline Good (vs v.good/excellent) & $\begin{array}{l}1.04(0.82,1.30) \\
0.77\end{array}$ & $\begin{array}{l}1.05(0.66,1.68) \\
0.84\end{array}$ & $\begin{array}{l}1.02(0.78,1.33) \\
0.87\end{array}$ \\
\hline Depressive symptoms (vs not) & $\begin{array}{l}1.28(1.05,1.56) \\
\mathbf{0 . 0 1}\end{array}$ & $\begin{array}{l}1.38(0.95,2.02) \\
0.09\end{array}$ & $\begin{array}{l}1.18(0.93,1.49) \\
0.17\end{array}$ \\
\hline ADLs (each additional ADL) & $\begin{array}{l}1.09(1.05,1.13) \\
<\mathbf{0 . 0 0 1}\end{array}$ & $\begin{array}{l}1.04(0.97,1.12) \\
0.26\end{array}$ & $\begin{array}{l}1.14(1.09,1.19) \\
<0.001\end{array}$ \\
\hline$R^{2}$ & 0.11 & 0.06 & 0.10 \\
\hline
\end{tabular}

Note: Participants in LTC at baseline interview $(n=77)$ are excluded. Depressive symptoms indicates a Geriatric Depression Scale score $\geq 5$ or where participant reports feeling depressed recently. ADLs is a count of 11 tasks participants did not perform independently from the Nottingham Extended Activities of Daily Living scale. $P$-values $<0.05$ are indicated in bold

${ }^{\text {a }}$ People with missing data about living situation were those who completed a Core questionnaire

likelihood of LTC entry once adjusted for other factors. Greater numbers of women in LTC may be explained instead by women often being married/partnered to older men who die before them, then because they live longer, they stay longer in LTC [29], and also by other factors correlated to gender but where numbers were inadequate to reach significance in the models. Gender was not a significant factor associated with receipt of services in the LiLACS-NZ study after adjustment for living arrangement and marital status [31]. Nevertheless, international studies suggest that some factors are more important for men and women, respectively. For example, being unmarried, living alone and incontinence are associated with greater likelihood of entry to LTC among men, while functional impairment carries a higher likelihood among women [2]. Elsewhere, the association between LTC entry and widowhood is linked to gender and is time-dependent, particularly within the first month of widowhood when older men are at greater likelihood of LTC entry [51, 52].

Thirdly, this study demonstrates that in NZ, no single information source could identify all participants who enter LTC. This is previously reported [53], and continues to have repercussions for monitoring public health and service utilisation. In the current study the most complete source was the subsidy data, finding 199/ 278 (69\%) of those who entered LTC during the study period. However Government subsidies are available only for residents who are deemed eligible for financial assistance after a care needs assessment and an assessment of their assets. Those in lower-level care paying entirely privately are thus not captured from subsidy data and are often omitted from utilisation reports [53]. Some under-reporting is thus possible even using six different data sources. InterRAI data, although introduced after the study start, were next most complete, however the source contributing the most additional information was the death registry data. In all, the three-way combination of subsidy, place of death and hospital discharge data found $247 / 278$ (89\%) of those recognised as entering LTC.

\section{Limitations}

There are several limitations of this study. The numbers who entered LTC may be underestimated because 
interRAI assessments were introduced after study inception, and place of death and residence in the death registry data were accessed only until December 2016. The study was conducted in only one region of NZ. The variables examined were restricted to characteristics collected in the core questions in the LiLACS-NZ baseline questionnaire with one exception, living situation, which was in the full questionnaire only. In consequence, receipt of supports (informal or formal) at baseline, blood results and physical assessment were too incomplete for modelling. Changes occurring after baseline and gathered in waves $2-6$, such as having a stroke or losing a spouse, were not included in the models. Nor was time to entry to LTC considered in competing risks models [54] because date of entry to LTC was not available. The study does not distinguish between type of LTC stay, for example long- or short-term, high- or low-level, palliative or dementia care, and nor were individual preferences, family expectations or values considered. Future research is needed to examine predictive factors for separate levels of care and related changes over time, as well as to examine participant characteristics which trigger immediate entry to LTC. Finally, fewer Māori, together with the smaller proportion of Māori living alone [55, 56] and the greater proportion of data missing for Māori (because of higher use of the core questionnaire) may have reduced the power of the study and made type II errors more likely.

\section{Conclusions}

Non-Māori people age over 80 years entered LTC at almost twice the rate of Māori during the 6 years of follow-up in this study, after adjustment for important correlates. Factors associated with LTC entry differed between Māori and non-Māori participants, with factors among non-Māori being similar to those identified in overseas studies. For our indigenous peoples, factors other than disability were important and this finding may be related to cultural choices and values. Informed discussion about access to and appropriateness of support services for older people and their carers - in LTC settings and at home - is needed.

\section{Supplementary Information}

The online version contains supplementary material available at https://doi. org/10.1186/s12889-020-09786-z.

Additional file 1. Primary data sources. Describes the data sources used for the risk factors and the endpoint of interest, i.e. entry to LTC.

\section{Abbreviations}

95\%Cl: 95\% confidence interval; ADL: Activity of Daily Living; CCPS: Contracted Care Payment System; GDS: Geriatric Depression Scale; HC: interRAI Home Care Form; interRAl: international Resident Assessment Instrument; LiLACS-NZ: Life and Living in Advanced Age, a Cohort Study in New Zealand; LTC: Long-term care; LTCF : interRAI Long Term Care Facility
Form; MoH: Ministry of Health; NEADL: Nottingham Extended Activities of Daily Living Scale; NZ: New Zealand; OECD: Organisation for Economic Cooperation and Development; RR: Relative risk; SD: standard deviation

\section{Acknowledgements}

The authors acknowledge and thank all participants and their whānau/families for their time and contribution to the principal study. The Rōpū Kaitiaki (Hone Kameta, Florence Kameta, Betty McPherson, Te Kaanga Skipper, Paea Smith, Laiana Reynolds, Waiora Port) oversaw the project from feasibility and throughout recruitment. We particularly honour the passing of Hone Kameta, Betty MacPherson and Paea Smith during the project. Elizabeth Robinson guided early biostatistical planning and Rudi Westendorp gave advice at the planning stages. We also acknowledge many others in the Department of Geriatric Medicine, School of Population Health, School of Nursing and James Henare Mãori Research Centre at the University of Auckland, and from the Waitematā District Health Board for their ongoing guidance.

\section{Authors' contributions}

The research question was raised by JBB, discussed and framed up by $\mathrm{MH}$, $J W, N K, Z W, S M, M J C, O M, R T, M M L, M G$ and JBB. JBB and MJC arranged funding for this studentship. $\mathrm{MH}$ undertook the literature review, descriptive analyses, contributed to modelling and prepared the manuscript. SM assembled the data and undertook analyses. ZW advised and assisted with analyses. NK, MJC and JBB provided oversight throughout. OM and MML provided important Mãori perspectives while JW, RT and MG contributed contextual and interpretative comment. All authors provided critical review and have read and approved the final manuscript.

\section{Funding}

The main project was supported by the Health Research Council of New Zealand (HRC09/06B), Ngā Pae o te Māramatanga (the New Zealand National Centre for Research Excellence for Māori) and New Zealand's Ministry of Health. Funding for this work was provided by a University of Auckland Summer Studentship. The funders played no role in the design of the study, in data collection, analysis, interpretation of data or in manuscript preparation.

\section{Availability of data and materials}

The datasets generated and/or analysed during the current study are not publicly available due to the personal and sensitive nature of some of the information, and because no consent was obtained from participants at the time the study commenced. Bona fide researchers who have a research question and wish to make use of the data should contact the corresponding author in the first instance.

Publicly available data, including hospitalisations, subsidy payments, interRAl assessments and death registration records may be obtained through the appropriate government sources following ethics and approval processes.

\section{Ethics approval and consent to participate}

Written informed consent was obtained from participants and ethical approval was granted by New Zealand's Northern X Regional Ethics Committee NXT09/09/88. All data were de-identified.

Consent for publication

Not applicable.

\section{Competing interests}

The authors declare that they have no competing interests.

\section{Author details}

${ }^{1}$ Department of Geriatric Medicine, University of Auckland, C/- Waitematā District Health Board, Takapuna, PO Box 93 503, Auckland, New Zealand.

${ }^{2}$ School of Population Health, University of Auckland, Auckland, New Zealand. ${ }^{3}$ Waitematā District Health Board, Auckland, New Zealand.

${ }^{4}$ Auckland District Health Board, Auckland, New Zealand. ${ }^{5}$ James Henare Māori Research Centre, University of Auckland, Auckland, New Zealand.

${ }^{6}$ School of Nursing, University of Auckland, Auckland, New Zealand. 
Received: 7 October 2019 Accepted: 28 October 2020 Published online: 06 January 2021

\section{References}

1. Andel R, Hyer K, Slack A. Risk factors for nursing home placement in older adults with and without dementia. J Aging Health. 2007;19(2):213-28.

2. Luppa M, Luck T, Weyerer S, König H-H, Brähler E, Riedel-Heller SG. Prediction of institutionalization in the elderly. A systematic review. Age Ageing. 2009:39(1):31-8.

3. Statistics New Zealand. Demographic Projections. Wellington: Statistics New Zealand; 2012

4. Broad JB, Ashton T, Gott M, McLeod H, Davis PB, Connolly MJ. Likelihood of residential aged care use in later life: a simple approach to estimation with international comparison. Aust N Z J Public Health. 2015;39(4):374-9.

5. Broad JB, Gott M, Kim H, Boyd M, Chen H, Connolly MJ. Where do people die? An international comparison of the percentage of deaths occurring in hospital and residential aged care settings in 45 populations, using published and available statistics. Int J Public Health. 2013;58(2):257-67.

6. OECD. Long-term Care for Older People. Paris: OECD Publishing; 2005.

7. Nakanishi M, Niimura J, Endo K, Nishida A. Regional supply of nursing home and hospital beds determine discharge destination of nursing home residents in Japan. J Am Med Dir Assoc. 2016;17(7):672 e1-5.

8. Rodríguez-Sánchez B, Angelini V, Feenstra T, Alessie RJM. Diabetesassociated factors as predictors of nursing home admission and costs in the elderly across Europe. J Am Med Dir Assoc. 2017;18(1):74-82.

9. Buchanan RJ, Rosenthal M, Graber DR, Wang S, Kim MS. Racial and ethnic comparisons of nursing home residents at admission. J Am Med Dir Assoc. 2008;9(8):568-79.

10. Phillips B, Daniels J, Woodward A, Blakely T, Taylor R, Morrell S. Mortality trends in Australian Aboriginal peoples and New Zealand Maori. Popul Health Metrics. 2017;15(1):25.

11. Goodman A, Fleming K, Markwick N, Morrison T, Lagimodiere L, Kerr T, et al. "They treated me like crap and I know it was because I was Native": The healthcare experiences of Aboriginal peoples living in Vancouver's inner city. Soc Sci Med. 2017;178:87-94.

12. Schuch HS, Haag DG, Kapellas K, Arantes R, Peres MA, Thomson WM, et al. The magnitude of indigenous and non-indigenous oral health inequalities in Brazil, New Zealand and Australia. Community Dent Oral Epidemiol. 2017; 45(5):434-41.

13. Hayman KJ, Kerse N, Dyall L, Kēpa M, Teh R, Wham C, et al. Life and living in advanced age: A cohort study in New Zealand -Te Puāwaitanga o Nga Tapuwae Kia Ora Tonu, LiLACS NZ: Study protocol. BMC Geriatr. 2012;12(33).

14. Kerse N, Muru-Lanning M, Rolleston A, Teh R. Life and Living in Advanced Age: A Cohort Study in New Zealand, Te Puawaitanga o Ngā Tapuwae Kia Ora Tonu (LiLACS NZ). In: Pachana NA, editor. Encyclopedia of Geropsychology. Singapore: Springer Singapore; 2015. p. 1-5.

15. Durie MH. Kaumātuatanga. Reciprocity: Maori elderly and whānau. New Zeal J Psychol. 1999;28(2):102-6.

16. Hirini PR, Flett RA, Kazantzis N, Long NR, Millar MA, MacDonald C. Health care needs for older Māori: A study of Kaumātua and kuia. Soc Pol J N Z 1999;13:136-53.

17. Tinetti ME, Williams CS. Falls, injuries due to falls, and the risk of admission to a nursing home. New Engl J Med. 1997;337(18):1279-84.

18. Betini RS, Hirdes JP, Lero DS, Cadell S, Poss J. Heckman G. A longitudinal study looking at and beyond care recipient health as a predictor of long term care home admission. BMC Health Serv Res. 2017;17(1):709.

19. Grundy E, Jitlal M. Socio-demographic variations in moves to institutional care 1991-2001: a record linkage study from England and Wales. Age Ageing. 2007;36(4):424-30

20. Boyd M, Broad JB, Kerse N, Foster S, von Randow M, Lay-Yee R, et al. Twenty-year trends in dependency in residential aged care in Auckland, New Zealand: a descriptive study. J Am Med Dir Assoc. 2011;12(7):535-40.

21. Kauppi M, Raitanen J, Stenholm S, Aaltonen M, Enroth L, Jylhä M. Predictors of long-term care among nonagenarians: the vitality $90+$ study with linked data of the care registers. Aging Clin Exp Res. 2018;30(8):913-9.

22. Luppa M, Riedel-Heller SG, Luck T, Wiese B, van den Bussche H, Haller F, et al. Age-related predictors of institutionalization: results of the German study on ageing, cognition and dementia in primary care patients (AgeCoDe). Soc Psychiatry Psychiatr Epidemiol. 2012;47(2):263-70.
23. Schluter PJ, Ward C, Arnold EP, Scrase R, Jamieson HA. Urinary incontinence, but not fecal incontinence, is a risk factor for admission to aged residential care of older persons in New Zealand. Neurourol Urodyn. 2017;36(6):1588-95.

24. Jorgensen D, Arksey $H$, Parsons M, Senior $H$, Thomas D. Why do older people in New Zealand enter residential care rather than choosing to remain at home, and who makes that decision? Ageing Int. 2009;34(1): 15-32.

25. Jamieson H, Abey-Nesbit R, Bergler U, Keeling S, Schluter PJ, Scrase R, et al. Evaluating the influence of social factors on aged residential care admission in a national home care assessment database of older adults. J Am Med Dir Assoc. 2019;20(11):1419-24.

26. Ministry of Health. In: Ministry of Health, editor. Tatau Kahukura: Maori Health Chart Book 2015 (3rd edition). Wellington; 2015.

27. Ellison-Loschmann L, Pearce N. Improving access to health care among New Zealand's Maori population. Am J Public Health. 2006;96(4):612-7.

28. Statistics New Zealand. National Ethnic Population Projections: 2013(base)2038. Wellington Statistics New Zealand 2015.

29. Statistics New Zealand. Living outside the norm: An analysis of people living in temporary and communal dwellings, 2013 Census. Wellington: Statistics New Zealand; 2015.

30. Lapsley H, Hayman KJ, Muru-Lanning ML, Moyes SA, Keeling S, Edlin R, et al. Caregiving, ethnicity and gender in Māori and non-Māori New Zealanders of advanced age: Findings from Li LACS NZ Kaiāwhina (Love and Support) study. Australas J Ageing. 2020;39(1):e1-8.

31. Lapsley H, Kerse N, Moyes SA, Keeling S, Muru-Lanning ML, Wiles J, et al. Do household living arrangements explain gender and ethnicity differences in receipt of support services? Findings from LiLACS NZ Māori and non-Māori advanced age cohorts. Ageing Soc. 2018;40(5):1004-20.

32. Durie MH. A Maori perspective of health. Soc Sci Med. 1985;20(5):483-6.

33. Walker R. Ka Whawhai Tonu Matou: Struggle Without End. Auckland: Penguin; 1990.

34. Dyall L, Kepa M, Hayman K, Teh R, Moyes S, Broad JB, et al. Engagement and recruitment of Māori and non-Māori people of advanced age to LiLACS NZ. Aust N Z J Public Health. 2013;37(2):124-31.

35. Gott M, Moeke-Maxwell T, Williams L, Black S, Trussardi G, Wiles J, et al. Te Pakeketanga: living and dying in advanced age--a study protocol. BMC Palliat Care. 2015;14:74.

36. Schluter PJ, Ahuriri-Driscoll A, Anderson TJ, Beere P, Brown J, DalrympleAlford J, et al. Comprehensive clinical assessment of home-based older persons within New Zealand: an epidemiological profile of a national crosssection. Aust N Z J Public Health. 2016;40(4):349-55.

37. Statistics New Zealand. Demographic Aspects of New Zealand's Ageing Population. Wellington: Statistics New Zealand; 2006.

38. Brazier JE, Roberts J. The estimation of a preference-based measure of health from the SF-12. Med Care. 2004:42(9):851-9.

39. Essink-Bot ML, Krabbe PF, Bonsel GJ, Aaronson NK. An empirical comparison of four generic health status measures. The Nottingham Health Profile, the Medical Outcomes Study 36-item Short-Form Health Survey, the COOP/ WONCA charts, and the EuroQol instrument. Med Care. 1997:35(5):522-37.

40. Sheikh JI, Yesavage JA. Geriatric Depression Scale (GDS): recent evidence and development of a shorter version. Clin Gerontol. 1986;5(1-2):165-73.

41. Marshall RJ. Scaled rectangle diagrams can be used to visualize clinical and epidemiological data. J Clin Epidemiol. 2005;58(10):974-81.

42. McNutt L-A, Wu C, Xue X, Hafner JP. Estimating the relative risk in cohort studies and clinical trials of common outcomes. Am J Epidemiol. 2003; 157(10):940-3.

43. Zhang D. A coefficient of determination for generalized linear models. Am Stat. 2017;71(4):310-6.

44. Kerse N, Lapsley H, Moyes S, Mules R, NZ L. Intervals of care need: Need for care and support in advanced age: LiLACS NZ. Auckland: School of Population Health, The University of Auckland; 2017. Available online from https://www.fmhs.auckland.ac.nz/assets/fmhs/faculty/lilacs/docs/Intervals-ofCare-Need.pdf.

45. Ministry of Health. Use of health services by older people: Wellington, Ministry of Health; 2017. Available online at https://www.health.govt.nz/nzhealth-statistics/health-statistics-and-data-sets/older-peoples-health-dataand-stats/use-health-services-older-people.

46. Gott M, Allen R, Moeke-Maxwell T, Gardiner C, Robinson J. 'No matter what the cost': A qualitative study of the financial costs faced by family and whānau caregivers within a palliative care context. Palliat Med. 2015:29(6): 518-28. 
47. Williams LA, Moeke-Maxwell T, Wiles J, Black S, Trussardi G, Kerse N, et al. How family caregivers help older relatives navigate statutory services at the end of life: a descriptive qualitative study. Palliat Med. 2018;32(6):1124-32.

48. Harris $Y$. Depression as a risk factor for nursing home admission among older individuals. J Am Med Dir Assoc. 2007;8(1):14-20.

49. Onder G, Liperoti R, Soldato M, Cipriani MC, Bernabei R, Landi F. Depression and risk of nursing home admission among older adults in home care in Europe: results from the Aged in Home Care (AdHOC) study. J Clin Psychiatry. 2007;68(9):1392-8.

50. Prince MJ, Harwood RH, Blizard RA, Thomas A, Mann AH. Impairment, disability and handicap as risk factors for depression in old age. The Gospel Oak Project V. Psychol Med. 1997;27(2):311-21.

51. Noël-Miller C. Spousal loss, children, and the risk of nursing home admission. J Gerontol Ser B Psychol Sci Soc Sci. 2010;65B(3):370-80.

52. Nihtilä $E$, Martikainen $P$. Institutionalization of older adults after the death of a spouse. Am J Public Health. 2008;98(7):1228-34.

53. Broad JB, Ashton T, Lumley T, Connolly MJ. Reports of the proportion of older people living in long-term care: a cautionary tale from New Zealand. Aust N Z J Public Health. 2013;37(3):264-71.

54. Enroth L, Aaltonen M, Raitanen J, Nosraty L, Jylhä M. Does use of long-term care differ between occupational classes among the oldest old? Vitality $90+$ Study. Eur J Ageing. 2018;15(2):143-53.

55. Dyall L, Kēpa M, Teh R, Mules R, Moyes SA, Wham C, et al. Cultural and social factors and quality of life of Maori in advanced age. Te puawaitanga o nga tapuwae kia ora tonu - Life and living in advanced age: a cohort study in New Zealand (LiLACS NZ). N Z Med J. 2014;127(1393):62-79.

56. Kerse N, Teh R, Moyes SA, Dyall L, Wiles JL, Kepa M, et al. Socioeconomic correlates of quality of life for non-Maori in advanced age: Te Puawaitanga - Nga Tapuwae Kia ora Tonu. Life and Living in Advanced Age: a Cohort Study in New Zealand (LiLACS NZ). N Z Med J. 2016;129(1441):18-32.

\section{Publisher's Note}

Springer Nature remains neutral with regard to jurisdictional claims in published maps and institutional affiliations.

Ready to submit your research? Choose BMC and benefit from:

- fast, convenient online submission

- thorough peer review by experienced researchers in your field

- rapid publication on acceptance

- support for research data, including large and complex data types

- gold Open Access which fosters wider collaboration and increased citations

- maximum visibility for your research: over $100 \mathrm{M}$ website views per year

At $\mathrm{BMC}$, research is always in progress.

Learn more biomedcentral.com/submissions 